Z. klin. Chem. u. klin. Biochem.

8. Jg., S. $186-189$, Mai 1970

\title{
Verteilung von Kininogen in Serum und Geweben bei Ratten und anderen Säugetieren
}

\author{
Von E. Werle und P. ZACH \\ Aus dem Institut fïr Klinische Chemie und Klinische Biochemie der Universität München (Direktor: Prof. Dr. Dr. E. Werle) \\ (Eingegangen am 28. Februar 1970) \\ Wir untersuchten Serum und Organe von Katze, Kaninchen, Meerschweinchen und weiblichen Ratten auf ihren Kininogengehalt und \\ fanden bei allen Tierarten unter Berücksichtigung des Blutgehaltes die höchsten Werte in der Lunge, gefolgt von Niere, Haut und Herz. \\ Im traumatischen Schock war bei weiblichen Ratten ein Kininogen-Anstieg im Serum auf das 3 fache und in den Organen auf das Doppelte \\ bei gleichzeitiger Vermehrung der freien Kinine im Serum zu beobachten, wobei die Zunahme in der Leber am größten war. In kẹinem \\ der untersuchten Organe war der Kininogengehalt vermindert. Im protrahierten Schock zeichnete sich eine Kininogenanhäufung in Niere, \\ Haut und Jejunum ab. Ein Hinweis auf den Bildungsort des Kininogens oder auf ein besonderes Kininogendepot ergab sich nicht.
}

\section{The distribution of kininogen in the serum and tissues of rats and other mammals}

Kininogen concentrations were studied in the serum and organs of the cat, rabbit, guinea pig and female rat. Allowing for the blood content of the organs, the highest values for all animals were found in the lungs, followed by kidneys, skin and heart. In traumatic shock, the serum kininogen of female rats was increased three-fold, and the concentrations in the organs were doubled with a simultaneous rise in the level of free kinins, which was highest in the liver. There was no decrease in kininogen in any of the organs studied. In protracted shock, there was an accumulation of kininogen in the kidneys, skin and jujenum. No evidence was obtained for a site of synthesis or special storage site for kininogen.

Eine Beteiligung des Kallikrein-Kinin-Systems an verschiedenen pathologischen und physiologischen Reaktionen des Organismus ist nachgewiesen oder wird diskutiert (1). Kallikrein kommt im Blutplasma und in Geweben vor (z. B. in Pankreas, Gl. submaxillaris, Niere, Darmschleimhaut); sein Substrat, das Kininogen, findet sich im Plasma. Einen Hinweis auf den Ort der Kininogensynthese sahen Diniz und Carvalmo (1963) darin, daß nach $\mathrm{CCl}_{4}$-Intoxikation der Leber von Kaninchen der Plasmakininogenspiegel parallel zum Ausmaß der Leberschädigung abfiel (2). Untersuchungen über den Kininogengehalt von Plasma und Organen sind notwendig, um die Frage nach der Beteiligung des Systems an pathologischen und physiologischen Vorgängen beantworten zu können.

Nachfolgend werden die Ergebnisse unserer Bestimmungen des Kininogengehaltes von Serum und frischen Organen von Ratten und anderen Säugetieren mitgeteilt.

\section{Methode}

Es wird die Kininmenge bestimmt, die durch Einwirken von Trypsin auf Kininogen des Serums oder auf das in Geweben vorhandene Kininogen freigelegt wird.

Blut wird ohne Zusatz von Antikoagulantien nach Getinnung in Polyäthylengefäßen etwa $10 \mathrm{Min}$. lang bei $3000 \mathrm{U}$./Min. zentrifugiert und $1,0 \mathrm{~m} l$ vom überstehenden Serum $\mathrm{zu} 15,0 \mathrm{~m} / 0,1 \mathrm{M}$ Essigsäure gegeben. Die zu untersuchenden Gewebe $(0,5-1,0 \mathrm{~g})$ werden möglichst schnell nach Tötung der Tiere entnommen und auf Eis gekühlt. Nach Ermittlung ihres Frischgewichtes werden die Gewebe in Polyäthylengefäßen, die $15 \mathrm{ml}$ eisgekühlte $0,1 \mathrm{M}$ Essigsäure enthalten, 1 Min. lang im Ultraturrax homogenisiert (20000 U./Min.). Vom Serumansatz und den Homogenaten werden je $1,0 \mathrm{ml}$ zur quantitativen Eiweißbestimmung (Biuret) entnommen, der Rest wird $30 \mathrm{Min}$. lang auf $100^{\circ}$ erhitzt und danin mit etwa $0,6 \mathrm{~m} / 2 \mathrm{~N} \mathrm{NaOH}$ und $2,5 \mathrm{~m} / 0,3 \mathrm{M}$ Trispuffer $\mathrm{pH} 7,85$ auf
$\mathrm{pH}$ 7,85 eingestellt. Die anschließende Inkubation mit Trypsin (je $2 \mathrm{mg}$ krist. Trypure „Novo“, chymotrypsinfrei) zur Freisetzung des Kinins aus Kininogen erfolgt 25 Min. lang bei $37^{\circ}$. Durch Ansäuern mit je $1,4 \mathrm{ml} 2 \mathrm{~N} \mathrm{HCl}$ und erneute Inkubation (30 Min. bei $37^{\circ}$ ) wird das Trypsin zerstört. Die Proben werden mit etwa $1,0 \mathrm{ml} 2 \mathrm{~N} \mathrm{NaOH}$ auf $\mathrm{pH} 5,5-6$ eingestellt, scharf zentrifugiert (40000 U./Min.). Zur Abtrennung der Kinine wird der Überstand an Kationenaustauscher XE-64 (Säulenabmessung $4 \times 20 \mathrm{~mm}$ ) adsorbiert. Nach Waschen mit Wasser wird zuerst mit $5,0 \mathrm{ml} 1 \mathrm{M}$ und anschließend mit $5,0 \mathrm{~m} l 0,1 \mathrm{M}$ Ammoniumacetatpuffer $(\mathrm{pH}$ 8,6) eluiert und das Eluat rasch mit Essigsäure neutralisiert, um eine Zerstörung des Kinins im Alkalischen zu verhindem. Bei diesem Vorgehen wurde eine Potenzierung einer gegebenen Kininmenge durch unspezifische im „Verdauungsansatz" mit Trypsin entstandene Peptide nicht beobachtet.

Die quantitative Kininbestimmung erfolgt mit Hilfe synthetischen Bradykinins (Sandoz), welches ebenfalls chromatographiert und mit Ammoniumacetat eluiert wird. Die dabei vorgelegte Bradykininmenge wird jeweils quantitativ wiedergefunden.

Die Kininbestimmung effolgt am Uterus jungfräulicher, mit Östrogen $(0,5 \mathrm{mg} / \mathrm{kg})$ vorbehandelter Ratten. Der Uterus ist in temperierter $\left(37^{\circ}\right)$ JALONscher Lösung, welche mit $\mathrm{O}_{2} / \mathrm{CO}_{2}$ (85:15 v/v) durchperlt wird, suspendiert; der Badflüssigkeit sind Atropin und Antistin ${ }^{1}$ ) (1 mg bzw. $5 \mathrm{mg} / 10 l$ ) hinzugesetzt ${ }^{2}$ ).

Parallel zur Kininogenbestimmung wird neben dem Eiweißgehalt der Blutgebalt der untersuchten Gewebe spektrophotometrisch nach BüCHER (3) bestimmt. Nach Kenntnis des Hämatokrits läßt sich der Serumgehalt der Gewebe errechnen. Wird der Kininogengehalt dieser Serummenge bestimmt und vom Gesamtkininogen der Gewebe abgezogen, so erhält man den extravasalen Kininogengehalt der Organe.

Bei der Durchführung der angegebenen Methode in Glasgefäßen wurde von uns nur beim Serum eine durch Oberflächenkontakt bewirkte Kininliberierung beobachtet. Eine Entwicklung freier Kinine aus Organkininogen durch Glaskontakt wurde nicht festgestellt.

1) 2-Phenyl-benzyl-aminomethyl-imidazolin Ciba.

2) Orientierende Messungen nach Zusatz des Serotonin-Antagonisten Lysergsäurediäthylamid ergaben keine Änderung der Kininwerte. 
Tab. 1

Kininogenverteilung in Serum und Organen von Katze, Kaninchen, Meerschweinchen und Ratte (Normalwerte), angegeben in freilegbarem Kinin, bezogen a) auf Frischgewicht $(\mu \mathrm{g} / \mathrm{g}), \mathrm{b})$ auf Protein $(\mu \mathrm{g} / 100 \mathrm{mg})$

\begin{tabular}{|c|c|c|c|c|c|c|c|c|c|c|c|c|}
\hline a) & & Serum & Lunge & Leber & Niere & Milz & $\begin{array}{c}\text { Pan- } \\
\text { kreas }\end{array}$ & Jeju- & $\underset{\substack{\text { Musku- } \\
\text { latur }}}{\text {. }}$ & Haut & Herz & Hirn \\
\hline $\begin{array}{l}\text { Kaninchen }(n=2) \\
\text { Katze }(n=1) \\
\text { Meerschweinchen }(n=3)\end{array}$ & $\begin{array}{l}\overline{\bar{x}} \\
\overline{\mathbf{x}} \\
\overline{\mathbf{x}}\end{array}$ & $\begin{array}{r}7,4 \\
10,3 \\
8,6\end{array}$ & $\begin{array}{l}3,0 \\
4,2 \\
3,5\end{array}$ & $\begin{array}{l}1,2 \\
2,6 \\
1,5\end{array}$ & $\begin{array}{l}1,2 \\
2,1 \\
1,3\end{array}$ & $\begin{array}{l}0,9 \\
0,8 \\
0,5\end{array}$ & $\begin{array}{l}1,1 \\
0,9 \\
1,5\end{array}$ & $\begin{array}{l}0,6 \\
0,5 \\
0,6\end{array}$ & & \multicolumn{2}{|c|}{$\begin{array}{l}\text { nicht bestimmt } \\
\text { nicht bestimmt } \\
\text { nicht bestimmt }\end{array}$} & \\
\hline Ratte $(n=4)$ & $\overline{\mathbf{x}}$ & $\begin{aligned} & 7,7 \\
& s \pm 2,36 \\
&\end{aligned}$ & $\begin{array}{l}2,5 \\
0,63 \\
\end{array}$ & $\begin{array}{l}0,88 \\
0,39 \\
\end{array}$ & $\begin{array}{l}1,47 \\
0,63\end{array}$ & $\begin{array}{l}0,89 \\
0,66\end{array}$ & $\begin{array}{l}0,73 \\
0,5\end{array}$ & $\begin{array}{l}0,56 \\
0,26\end{array}$ & $\begin{array}{l}0,82 \\
0,46\end{array}$ & $\begin{array}{l}1,59 \\
1,03\end{array}$ & $\begin{array}{l}1,45 \\
0,8\end{array}$ & $\begin{array}{l}0,53 \\
0,3\end{array}$ \\
\hline b) & & Serum & Lunge & Leber & Niere & Milz & $\begin{array}{l}\text { Pan- } \\
\text { kreas }\end{array}$ & $\underset{\text { num }}{\text { Jeju- }}$ & $\begin{array}{c}\text { Musku- } \\
\text { latur }\end{array}$ & Haut & Herz & Hirn \\
\hline $\begin{array}{l}\text { Kaninchen }(n=2) \\
\text { Katze }(n=1) \\
\text { Meerschweinchen }(n=3)\end{array}$ & $\begin{array}{l}\overline{\bar{x}} \\
\overline{\mathbf{x}} \\
\overline{\mathbf{x}}\end{array}$ & $\begin{array}{r}9,9 \\
12,6 \\
17,0\end{array}$ & $\begin{array}{l}2,0 \\
2,4 \\
2,1\end{array}$ & $\begin{array}{l}0,5 \\
0,9 \\
0,8\end{array}$ & $\begin{array}{l}0,9 \\
1,2 \\
1,2\end{array}$ & $\begin{array}{l}0,6 \\
0,8 \\
0,4\end{array}$ & $\begin{array}{l}0,5 \\
0,6 \\
0,8\end{array}$ & $\begin{array}{l}0,4 \\
0,4 \\
0,5\end{array}$ & & \multicolumn{2}{|c|}{$\begin{array}{l}\text { nicht bestimmt } \\
\text { nicht bestimmt } \\
\text { nicht bestimmt }\end{array}$} & \\
\hline Ratte $(n=4)$ & $\overline{\mathbf{x}}$ & $\begin{array}{r}10,4 \\
\pm s 2,06 \\
\end{array}$ & $\begin{array}{l}1,38 \\
0,39 \\
\end{array}$ & $\begin{array}{l}0,38 \\
0,19 \\
\end{array}$ & $\begin{array}{l}0,79 \\
0,27\end{array}$ & $\begin{array}{l}0,46 \\
0,35\end{array}$ & $\begin{array}{l}0,37 \\
0,25\end{array}$ & $\begin{array}{l}0,27 \\
0,13\end{array}$ & & $\begin{array}{l}0,58 \\
0,34\end{array}$ & $\begin{array}{l}0,78 \\
0,47\end{array}$ & $\begin{array}{l}0,46 \\
0,31\end{array}$ \\
\hline
\end{tabular}

Im Kontrollversuch wurde jeweils die aus Serum und Organen durch Trypsin freigesetzte uterusaktive Substanz durch Carboxypeptidase B zerstört.

Zur Bestimmung des Kininogengehaltes von Serum und Organen wurden weibliche Ratten im Gewicht von $250-300 \mathrm{~g}$ durch Kopfschlag, Katzen, Kaninchen und Meerschweinchen mit Äther betäubt und dann entblutet.

\section{Ergebnisse}

Die ermittelten Werte sind in Tabelle 1 verzeichnet; die Mengen freilegbaren Kinins sind sowohl in Relation zum Frischgewicht als auch zum Eiweißgehalt der Organe angegeben. Bei Bestimmung des Kininogengehaltes von Rattenserum und -organen war auffällig, daß nur 4 von 13 Ratten eine den anderen untersuchten Tierarten vergleichbare Kininogenverteilung aufwiesen. Obwohi alle Ratten durch Kopfschlag betäubt und dann entblutet wurden, ergab sich bei 9 Ratten die in Tabelle 2 angeführte Verteilung.

Eine ähnliche Kininogenverteilung fanden wir bei Ratten nach Auslösung eines Trypsinschockes $(200 \mathrm{mg} / \mathrm{kg}$ i. v.) (Tab. 3).

Um die Kininogenverteilung an Ratten zu untersuchen, die prämortal keinem traumatischen Schock ausgesetzt waren, wählten wir folgendes Verfahren: 10 Ratten wurden durch intraperitoneale Urethan- bzw. Nembutalinjektion $(1,4 \mathrm{~g} / \mathrm{kg}$ bzw. $60 \mathrm{mg} / \mathrm{kg})$ narkotisiert. Nach Legen einer Trachealkanüle und zweier Carotiskatheter
Tab. 2

Kininogenverteilung bei Ratten im traumatischen Schock, angegeben in freilegbarem Kinin $(\overline{\mathbf{x}} \pm \mathbf{s}, n=9)$, bezogen a) auf Frischgewicht $(\mu \mathrm{g} / \mathrm{g}), \mathrm{b})$ auf Protein $(\mu \mathrm{g} / 100 \mathrm{mg})$

\begin{tabular}{|c|c|c|c|c|c|c|c|}
\hline & Serum & Lunge & Leber & Niere & Milz & $\begin{array}{l}\text { Pan- } \\
\text { kreas }\end{array}$ & $\begin{array}{l}\text { Jeju- } \\
\text { num }\end{array}$ \\
\hline a) & $\begin{array}{r}27,0 \\
\pm 10,2\end{array}$ & $\begin{array}{l}5,5 \\
1,78\end{array}$ & $\begin{array}{l}2,27 \\
1,03\end{array}$ & $\begin{array}{l}2,94 \\
1,73\end{array}$ & $\begin{array}{l}1,54 \\
0,55\end{array}$ & 1,12 & $\begin{array}{l}1,16 \\
0,38\end{array}$ \\
\hline b) & $\begin{array}{r}39,6 \\
\pm 17,5\end{array}$ & $\begin{array}{l}3,21 \\
1,02\end{array}$ & $\begin{array}{l}0,88 \\
0,49\end{array}$ & $\begin{array}{l}1,95 \\
1,06\end{array}$ & $\begin{array}{l}0,73 \\
0,27\end{array}$ & $\begin{array}{l}0,5 \\
0,35\end{array}$ & $\begin{array}{l}0,67 \\
0,24\end{array}$ \\
\hline
\end{tabular}

Tab. 3

Kininogenverteilung bei Ratten im Trypsinschock, angegeben in freilegbarem Kinin $(\overline{\mathbf{x}}, \mathfrak{n}=3)$, bezogen a) auf Frischgewicht $(\mu \mathrm{g} / \mathrm{g})$ b) auf Protein ( $\mu \mathrm{g} / 100 \mathrm{mg})$

\begin{tabular}{llllllll}
\hline & Serum & Lunge & Leber & Niere & Milz & $\begin{array}{c}\text { Pan- } \\
\text { kreas }\end{array}$ & $\begin{array}{l}\text { Jeju- } \\
\text { num }\end{array}$ \\
\hline a) & 28,6 & 5,3 & 2,17 & 4,76 & 1,22 & 1,56 & 1,2 \\
b) & 48,0 & 2,26 & 1,19 & 2,37 & 0,73 & 0,8 & 0,64 \\
\hline
\end{tabular}

wurde der Blutdruck gemessen. Die Körpertemperatur wurde konstant auf $37^{\circ}$ gehalten. $45 \mathrm{Min}$. nach Beendigung der operativen Maßnahmen wurden aus der A. carotis $1 \mathrm{ml}$ Blut, nach weiteren $45 \mathrm{Min}$. die Organe entnommen. Die dann ermittelten Serum- und Organkininogenwerte sind in Tabelle 4 angegeben.

Zum Zeitpunkt der Blutentnahme und kurz vor der Organentnahme schwankte der arterielle Blutdruck zwischen 90 und $105 \mathrm{~mm} \mathrm{Hg}$.

Tab. 4

Kininogenverteilung bei Ratten im protrahierten Schock, angegeben in freilegbarem Kinin $(\bar{x} \pm s, n=10)$, bezogen a) auf Frischgewicht ( $\mu \mathrm{g} / \mathrm{g})$, b) auf Protein $(\mu \mathrm{g} / 100 \mathrm{mg})$

\begin{tabular}{|c|c|c|c|c|c|c|c|c|c|c|}
\hline Serum & Lunge & Leber & Niere & Milz & Pankreas & Jejunum & Muskulatur & Haut & Herz & Hirn \\
\hline $\begin{array}{c}22,2 \\
6,35 \\
36,1 \\
7,1\end{array}$ & $\begin{array}{l}3,04 \\
0,92 \\
1,53 \\
0,54\end{array}$ & $\begin{array}{l}1,15 \\
0,72 \\
0,47 \\
0,37\end{array}$ & $\begin{array}{l}2,5 \\
1,03 \\
1,3 \\
0,53\end{array}$ & $\begin{array}{l}1,1 \\
0,85 \\
0,54 \\
0,49\end{array}$ & $\begin{array}{l}1,0 \\
0,5 \\
0,42 \\
0,37\end{array}$ & $\begin{array}{l}1,0 \\
0,71 \\
0,45 \\
0,4\end{array}$ & $\begin{array}{l}0,77 \\
0,43 \\
0,37 \\
0,22\end{array}$ & $\begin{array}{l}4,35 \\
1,32 \\
1,46 \\
0,43\end{array}$ & $\begin{array}{l}2,27 \\
0,52 \\
1,37 \\
0,34\end{array}$ & $\begin{array}{l}0,56 \\
0,16 \\
0,81 \\
0,36\end{array}$ \\
\hline
\end{tabular}

Tab. 5

Kininogengehalt der Organe von Katze, Kaninchen, Meerschweinchen und Ratte in Prozent des Blutkininogens (Normalwerte)

\begin{tabular}{|c|c|c|c|c|c|c|c|c|c|c|c|}
\hline & Blut & Lunge & Leber & Niere & Milz & $\begin{array}{c}\text { Pan- } \\
\text { kreas }\end{array}$ & Jeju- & $\underset{\text { latur }}{\text { Musku- }}$ & Haut & Herz & Hirn \\
\hline $\begin{array}{l}\text { Katze } \\
\text { Kaninchen } \\
\text { Meerschweinchen } \\
\text { Ratte }\end{array}$ & $\begin{array}{l}100 \\
100 \\
100 \\
100\end{array}$ & $\begin{array}{l}79 \\
83 \\
83 \\
65\end{array}$ & $\begin{array}{l}49 \\
33 \\
36 \\
23\end{array}$ & $\begin{array}{l}40 \\
32 \\
31 \\
38\end{array}$ & $\begin{array}{l}14 \\
24 \\
12 \\
23\end{array}$ & $\begin{array}{l}18 \\
30 \\
35 \\
19\end{array}$ & $\begin{array}{l}11 \\
15 \\
13 \\
14\end{array}$ & 21 & 41 & 38 & 14 \\
\hline
\end{tabular}


Tab. 6

Zunahme des Kininogengehaltes von Plasma und Organen bei Ratten im traumatischen und protrahierten Schock in Prozent des Normalwertes

\begin{tabular}{|c|c|c|c|c|c|c|c|c|c|c|c|}
\hline & Serum & Lunge & Leber & Niere & Milz & $\begin{array}{l}\text { Pan- } \\
\text { kreas }\end{array}$ & Jeju- & $\begin{array}{c}\text { Musku- } \\
\text { latur }\end{array}$ & Haut & Herz & Hirn \\
\hline ohne Schock $\quad(n=4)$ & 100 & 100 & 100 & 100 & 100 & 100 & 100 & 100 & 100 & 100 & 100 \\
\hline traum. Schock $(n=9)$ & 350 & 220 & 258 & 200 & 173 & 153 & 207 & \multicolumn{4}{|c|}{ nicht bestimmt } \\
\hline protr. Schock $(n=10)$ & 290 & 122 & 131 & 170 & 124 & 147 & 178 & 94 & 274 & 157 & 106 \\
\hline
\end{tabular}

\section{Diskussion}

Setzt man den Kininogengehalt von Vollblut (bei einem angenommenen Hämatokrit von 50) zum Kininogengehalt der Organe in Beziehung, so ergeben sich die in Tabelle 4 aufgeführten Verhältnisse. Es ist auffällig, daß sich bei allen untersuchten Tierarten nach dem Serum der höchste Kininogengehalt in der Lunge findet. Selbst Haut, Niere und Herz enthalten bei Ratten mehr Kininogen als die Leber, welche als wahtscheinlichster Syntheseort des Kininogens gilt. Weiterhin ist bemerkenswert, da $\beta$ alle Organe Kininogen, wenn auch in verschiedenen Mengen, enthalten. Diese Tatsache entspricht der Vorstellung, die man sich vom KallikreinKinin-System als beteiligtem Faktor beim Zustandekommen entzündlicher Vorgänge macht $(4,5)$. Eine Anhäufung des Kininogens in Lunge und Haut könnte die besondere Rolle des freigelegten Kinins bei allergischen Reaktionen (6), aber auch seine Beteiligung an Veränderungen der Kapillarpermeabilität $(7,8)$ und der Gewebsdurchblutung (9) erklären. Der hohe Kininogengehalt der Niere interessiert im Zusammenhang mit dem Vorkommen von Kallikrein und freiem Kinin in Niere und Harn (10). An der physiologischen Regulation der Coronardurchblutung scheinen die Kinine trotz hohen Kininogengehaltes des Herzmuskels nicht beteiligt zu sein (11).

Die ethöhten Serum- und Organkininogenwerte, die wit bei 9 von 14 Ratten beobachteten, entsprechen den Werten, die nach Auslösung eines Trypsinschockes festgestellt wurden. Es liegt nahe, diesen Anstieg im Serum auf das 3 fache und auf etwa das Doppelte in den Organen auf den traumatischen Schock zurückzuführen (vor dem Entbluten wurden die Tiere, wie erwähnt, durch Kopfschlag betäubt). Doch auch bei den 10 Ratten, die mit Urethan- bzw. Nembutal narkotisiert wurden, fand sich eine ähnliche Kininogenverteilung, wenn auch die ermittelten Werte um 20-30\% niedriger lagen. Der arterielle Blutdruck schwankte bei diesen Tieren infolge Narkose und operativer Eingriffe zwischen 90 und $105 \mathrm{~mm} \mathrm{Hg}$ und lag damit um etwa 20\% unterhalb der Norm. Eine Beeinflussung des Serumkininogenspiegels durch Urethan bzw. Nembutal erscheint uns unwahrscheinlich, da z. B. Hunde vor und nach Nembutal gleiche Serumkininogenwerte aufweisen. In diesem $\mathrm{Zu}-$ sammenhang erscheint es interessant, daß J. BRocKSTRDT nach experimentell gesetzter Verbrennung bei Ratten Serumkininogenwerte gleicher Größenordnung fand (12). Bei diesen 10 Ratten ergab die Bestimmung der freien Kinine nach OATES und Mitarbeitern (13) stark er- höhte Werte zwischen $0,04-0,17 \mu \mathrm{g} / \mathrm{m} l$ Blut. Fine Steigerung der Serumkininaseaktivität wurde nicht beobachtet.

Bei Ratten, Hunden und Kaninchen wurde nach anaphylaktischem, Endotoxin- und Entblutungsschock ein erhöhter Spiegel freier Kinine beobachtet, gleichzeitig zeigte sich jedoch ein Abfall des Serumkininogens bis um $30 \%(14,15,16,17)$. Ein hoher Serumkininspiegel bei gleichzeitiger Vermehrung des.Kininogens in Serum und Organen'von Ratten im traumatischen Schock erscheint deshalb überraschend. Ebenso ungeklärt ist aufgrund unserer Untersuchungen, aus welchem Speicher das Kininogen liberiert wird, das die Erhöhung des Blutspiegels verursacht.

Im traumatischen Schock steigen sowohl Serum- als auch Organkininogengehalt an (Tab. 1, 2). Bei Vergleich der Organkininogenwerte $(\mu \mathrm{g} / \mathrm{g})$ von Ratten ohne Schock, im Schock und im protrahierten Schock zeigte sich (Tab. 4), daß im Schock die Zunahme an Kininogen in der Leber am größten $(+260 \%)$ ist; im protrahierten Schock ist Kininogen in Niere, Jejunum und Haut stärker vermehrt als in den anderen Organen. Einen Hinweis auf einen Kininogenspeicher bzw. auf einen bevorzugten Syntheseort geben unsere Befunde nicht. Die Tatsache, da $B$ in allen Organen Kininogen gefunden wird, könnte darauf beruhen, da $B$ jedes Organ zur Synthese befähigt ist, wahrscheinlicher aber ist, da $\beta$ das Kininogen aus der Blutbahn in das Interstitium der Gewebe übertritt.

Ausgedehntere Bestimmungen des Kininogengehaltes von tierischen Geweben stammen von V. M. SARDESAI (18), wobei als Ausgangsmaterial käufliche Acetontrockenpulver verwendet und im wesentlichen nach Diniz und Carvalho aufgearbeitet wurden. Auch hier wurden wechselnde Mengen von Kininogen in den untersuchten Organen, nämlich Herz, Leber, Niere und Gehirn und zwat von Kaninchen, Rind, Schwein, Schaf und Taube festgestellt. Die höchste Menge fand sich jeweils beim Herzmuskel und nahm in der angeführten Organreihe ab, z. B. lauteten die Werte beim Kaninchen 29 (Herz); 13,9 (Leber); 8,4 (Niere); 2,6 (Gehirn) $\mu \mathrm{g} / \mathrm{g}$ Trockengewicht.

$\mathrm{Da}$ uns unbekannt ist, ob der Blutgehalt der Organe bei den Messungen berücksichtigt wurde, sind die Werte mit den unsrigen nicht ohne weiteres vergleichbar. So ist in unserer Aufstellung der Gehalt der Nieren meist höher oder doch mindestens ebenso hoch wie der der Leber, während bei SARDESAI die Werte für Leber meist etwa doppelt so boch liegen wie für die Niere. 
Nach dem gegenwärtigen Stand der Forschung gibt es im Blutplasma des Menschen und der Säugetiere zwei, wahrscheinlich sogar drei verschiedene Kininogene, die sich nicht nur im Molekulargewicht, sondern auch in ihrer Angreifbarkeit durch Kininogenasen unterscheiden. Es wird zu untersuchen sein, ob dje in den verschiedenen Organen nachgewiesenen Kininogene untereinander differenzierbar sind.

\section{Literatur}

1. Frey, E. K., H. Kraut und E. Werde, Das Kallikrein-KininSystem und scine Inhibitoren, Enke Verlag, Stuttgart (1968). 2. Diniz, C. R. und 1. F. Carvalho, Ann. N. Y. Acad. Se. 104, 77 (1963). - 3. Horrorst, H. J., F. H. Kreutz und TH. Bücher, Biochem. Z. 332, 18 (1959). - 4. Lewis, G. P., Ann. N. Y. Acad. Sc. 104, 236 (1963). - 5. MrLmon, K. L. und M. J. Cline, IIIrd International Pharmacological Congress, Sao Paulo, Abstracts (1966). - 6. Collier, H. O. J., G. W. L. James und P. J. Piper, J. Physiol., 180, 13 P (1965), - 7. Schachter, M., in: M. SCHACHTER, Polypeptides, Pcrgamon Press, London (1960). - 8. ERdös, E. G., Adv. Pharmac. 4, 1 (1966). - 9. MAson, D. T. und K. L. Melmon, Circulat. Res. 17, 106 (1956). - 10. WerLe, E. und
R. VoGer, Arch. internat. pharmacodyn. therap. 126, 171 (1960).

11. Bassenge, E., Habilitationsschrift, München (1969). 12. Brockstedt, J., nicht veröffentlicht. - 13. OAtes, J. A., K. Melmon, A. Sjoerdema, L. Gillfispiz and K. Mason, Lancet, London I/1964, 514. - 14. Cirstea, M., G. Suitaciu und I. Butulescu, Arch. internat. pharmacodyn. therap. 159, 1 (1966). 15. ERdös, E. G. und I. Miwa, Fed. Proc. 27, 1 (1968). - 16. Sardesal, V. M. und A. J. Walt, Pharm. Res. Comm. 1, 192 (1969). 17. Berry, H. E., J. G. Collier und J. R. Vane, Pharm. Res. Comm. 1, 139 (1969). - 18. Sardesax, V. M., Canad. J. Phys. and Pharm. 46, 77 (1968).

Prof. Dr. Dr. E. Werlc 8000 München 15

Nußbaumstraße 20 